\title{
Developing Community Engaged Research Practices in Family, School, and Community Partnerships
}

\author{
Michael P. Evans \\ Miami University, Ohio \\ USA
}

\begin{abstract}
As the field of family, school, and community partnerships continues to evolve, there is increasing recognition of the impact that parents, guardians, and communities can have on students, schools, and education systems-at-large when provided with opportunity to become authentically engaged. To further this evolution, there is a need for participatory approaches to research that directly support educational change. This article provides an overview of community engaged scholarship (CES) with a focus on the benefits, criticisms, and challenges that emerge from the utilization of this approach. Special attention is given to how CES intersects with existing efforts in the field of family, school, and community partnerships.
\end{abstract}

Keywords: community engaged scholarship, community-based research, family, school and community partnerships, family engagement 


\section{Introduction}

The field of family, school, and community partnerships has grown rapidly over the past thirty years. There is now widespread recognition of the value of home and school connections and the potential benefits for students, families, and educators. Research indicates that strong family and school relationships can improve students' academic achievement (Fan, 2010; Henderson \& Mapp, 2002; Sheldon, 2003); while perceptions of the quality of family-school interactions is also positively correlated with higher levels of trust between parents and educators (Adams \& Christenson, 2000). However, the creation of high quality family, school, and community partnerships is often difficult to achieve. Typically, educators are not well prepared for engaging with families or communities (Evans, 2013), and relational power dynamics among educators and families can be complicated by issues related to socioeconomic status (Lareau, 2011; Li, 2010), race and ethnicity (Bertrand, Freelon, \& Rogers, 2018), religious background (Huss-Keeler, 1997), or sexual orientation (Kosciw \& Diaz, 2008; Kroeger, 2006).

Continued research is necessary to support ongoing progress in the field of family, school, and community partnerships, but frequently the same inequitable power dynamics that arise in traditional family and school relations are also present in the relationships between researchers and communities. Many communities and schools seeking educational change grow weary of sporadic and unsustainable interactions with universities or researchers. For families and communities, there is a need for actionable knowledge. "Research, in this sense, is not only the production of original ideas and new knowledge (as it is normally defined in academia and other knowledge-based institutions). It is also something simpler and deeper. It is the capacity to systematically increase the horizons of one's current knowledge, in relation to some task, goal or aspiration" (Appadurai, 2006, p. 176). With these concerns in mind, community engaged scholarship (CES) is one viable alternative for researchers, communities, and educators who are seeking to advance the field and address social inequities. This article seeks to provide an introduction to CES, address the benefits and challenges to CES approaches, and discuss specifically how community-based research can enhance family, school, and community partnerships.

\section{Toward Authentic Partnerships and Collaborations}

The concepts of partnership and collaboration are inherently appealing to many people. As humans, we are supposed to recognize the value of working together, and as a result, it is not uncommon for people or organizations to use this terminology to describe working relationships. After all, who wants to send their child to a school that doesn't value collaboration? But what do these terms really mean and, perhaps more importantly, how are they enacted in practice? This is an important question as schools and districts are increasingly required to demonstrate how they develop and support family involvement (Evans \& Radina, 2014). Auerbach and Collier's (2012) case study of Families Supporting Success (FSP), a family literacy program focused on immigrant parents of elementary school children in Los Angeles, is one example of how the rhetoric of partnership may be used to tout programs that are, in reality, implemented with the absence of authentic family or community voice. In this situation, parent participants in FSP were exposed to a parent education curriculum narrowly focused on improving reading scores for high-stakes testing. The program failed to have a measurable impact on student achievement, but families and staff did cite the value of unintended consequences, such as an improved school climate generated as a result of relationships that were forged in FSP. The pressures of top down policy initiatives coupled with the traditional framing of home and school relationships as transactional exchanges often hinder efforts to implement more authentic partnership work (Crowson \& Boyd, 2001; Evans \& Radina, 2014). Moreover, many existing partnership models 
tend to privilege white, middle-class norms and schoolcentric agendas. The result is that the beliefs and practices of historically marginalized parents frequently go unrecognized or are simply not valued (Cooper \& Christie, 2005).

Fortunately, the field of family, school, and community partnerships continues to evolve with a growing recognition of the need for more authentic and inclusive partnerships and collaborations. Central to these efforts has been an emphasis on relationship building and power sharing among education stakeholders (Warren, Hong, Rubin, \& Uy, 2009). In recent years, community organizing has played a significant role in providing a means for low-income and minority families to become more authentically engaged with schools and education policy (Shirley, 2009; Warren \& Mapp, 2011). Many educational leaders at all levels are also starting to recognize the importance of relationship building (Auerbach, 2012). In 2014, the Department of Education released the Dual Capacity Building Framework at the National Family Engagement Conference in Cincinnati, Ohio. In contrast to previous federal policies related to family engagement that were more prescriptive in nature (Rogers, 2006), this new framework was more focused on the conditions that are necessary for effective family engagement. In recognition of the complex and often tenuous relationship between schools and families, the framework argues that programs and policies, "must focus on building the capacities of both staff and families to engage in partnerships" (Mapp \& Kutter, 2014, p. 12). The new framework is notable in its recognition of mutual accountability and its shift from service-oriented practices to more authentic partnership work (Anderson, 2009).

\section{The Spectrum of Community-Engaged Scholarship}

To continue to grow the field and support these shifts in thinking about families as collaborators, scholars interested in this work can also seek to develop more authentic partnerships, including introducing and supporting community-engaged research. What follows is a summary of CES, including a discussion of its benefits, common criticisms, and challenges in practice. These sections are supported with examples from the fields of community health and the broader field of education. CES has been practiced across various disciplines for many years, but it has yet to emerge as a commonly used methodology for family, school, and community partnership work. The articles in this special issue of The Journal of Family Diversity in Education (JFDE) offer examples of nascent efforts to in the field to practice CES.

There are many forms of research that may fit under the broader category for CES including: collaborative research, community engaged research, participatory action research, participatory design research, digital storytelling, critical participatory action research, 
community-based participatory research, and youth participatory action research. Within these varied approaches, research partners may utilize both quantitative and qualitative techniques.

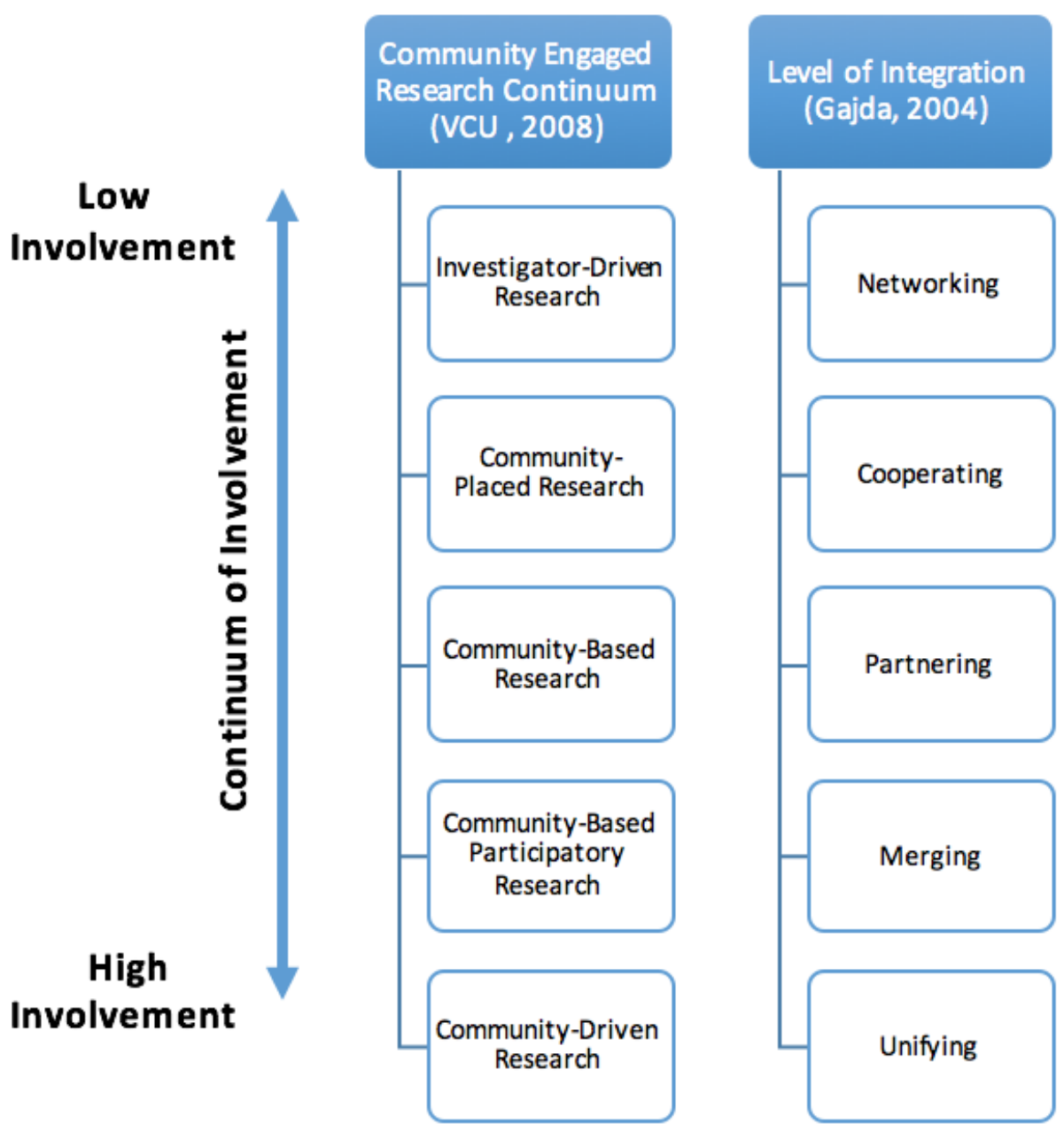

Figure1. Engagement Continuum in Community-Engaged Scholarship

The level of stakeholder engagement also varies, as CES exists on a continuum and it is important to understand the nuanced variations across approaches. Figure 1 (see above) includes a representation of this continuum developed at the Virginia Commonwealth University Center for Clinical and Translational Research (Hacker, 2013). The continuum alludes to the fact that research claiming engagement or involvement does not necessarily signal ongoing participation. While some approaches involve researchers and communities being actively engaged throughout the entire research process, in others, participation is more variable and contingent on factors such as time, interest, and expertise.

Similarly, I argue that even within the categories that typically seek fuller participation there can be different levels of partner integration. This is also represented in Figure 1, by the inclusion of Rebecca Gajda's valuable work on the topic of collaboration and strategic alliances. In this work Gajda identifies five levels of integration: networking, cooperating, partnering, 
merging and unifying. These levels are determined based on an evaluation of purpose(s), strategies and tasks, leadership and decision-making, and interpersonal/communication norms. With lower levels of integration there may be consultation, but there is no formal structure and communication between partners may be sporadic. At the opposite end of the spectrum there are higher degrees of commitment and deeper investments in the relationships. Thus, one participatory action research (PAR) project might involve researchers and communities working closely together throughout every phase of the research cycle, from the inception of the research questions, through development and implementation of the methodology, to the dissemination of the findings. Another PAR project may involve the community in the development of the research questions, have limited involvement in the data collection process, but reengage for the analysis and creation of the final products. Highlighting these differences is not meant to disparage or elevate a particular approach, but rather to acknowledge variations across CES. As will be discussed in the next section, the adherence to some basic core principles is what is most important when evaluating the quality of CES.

\section{Basic Principles of CES}

As noted, there are multiple research approaches that involve communities, but this does not mean that they are necessarily examples of CES. There are some underlying principles that typically inform CES approaches. First, CES involves collaboration between researchers and community members. What is significant here is that the relationship between the researcher and community is fundamentally transformed from the traditional model of research being conducted on or in a community to research that is conducted with a community. In essence, the community is no longer framed as an object of study, but as an active and agentive partner. Peralta writes, "Communities and researchers should interact through a subject to subject relationship.... there is reciprocity, mutuality, and recognition of the other" (2017, p. 50). As stated above, this may include partnering to identify research questions, co-developing and implementing research methodologies, analysis of data, and/or the dissemination of the findings.

Second, CES does not rely on narrow definitions of what constitutes knowledge and recognizes the complex power dynamics that often drive what information "counts" in various community or policy circles. To draw from a commonly cited example in the field of family, school, and community partnerships we can look to the work on "funds of knowledge" by Luis Moll and colleagues (1992). Moll et al. identify vast cultural and cognitive knowledge resources in communities that typically go unrecognized by educators, who instead tend to rely on myopic, deficit-based perspectives. Examples of knowledge in Moll's study that have been overlooked include information related to economics, medicine, repair skills, household management, religion, and science. Systemic injustices are so deeply embedded in the dominant cultures of the United States that knowledge contributions of "othered" populations are actively disparaged, ignored, or go unseen. Yosso provides a more explicit analysis of the role of racism in traditional knowledge production through her application of critical race theory (CRT) to the concept of community cultural wealth (2005). 
CRT shifts the center of focus from notions of White, middle class culture to the cultures of Communities of Color.... Indeed, a CRT lens can 'see' that Communities of Color nurture cultural wealth through at least 6 forms of capital such as aspirational, navigational, social, linguistic, familial, and resistant capital (see Delgado Bernal, 1997, 2001; Auerbach, 2001; Stanton-Salazar, 2001; Solórzano \& Delgado Bernal, 2001; Faulstich Orellana, 2003). These various forms of capital are not mutually exclusive or static, but rather are dynamic processes that build on one another as part of community cultural wealth (p. 77).

In CES, knowledge does not originate in the academy nor is it something to be discovered by outside researchers. Rather, CES operates from the assumption that all communities possess and create knowledge that is valuable. Moreover, this knowledge is perceived as essential for effectively responding to social issues through the research process.

Third, in addition to recognizing multiple forms of knowledge, CES is also inclusive of various methodologies and forms of research dissemination. Surveys, interviews, and observations can be supplemented or supplanted by digital storytelling, the visual arts, or social theater (Denzin, 2017). A peer-reviewed journal article, which is highly valued in the academy, may become secondary to an op-ed, white paper, or public art exhibition (e.g., Sloane \& Wallin, 2013). The target audience for CES can also be varied and might include academics, policymakers, educators, or other members of the local community. For example, researchers at UCLA/IDEA have worked with various community stakeholders over the past decade to develop a series of Educational Opportunity Reports focused on topics such as education funding, race, and college access (Rogers, Fanelli, Freelon, Medina, Bertrand, \& Del Razo, 2010). These reports serve as both a resource for families and as a clearinghouse for education-related statistics that can be used to advocate for change with state policymakers. At UC Santa Cruz there is an annual Youth Empowerment Institute (YEI) focused on high school girls interested in various social justice issues facing their communities. YEI seeks to empower young women as leaders and to address the gender gap in STEM fields. In the past, these young women have researched topics like college access and justice issues related to food. To disseminate their findings and raise awareness among other youth, they developed mobile apps that are now available in the Apple iTunes store and on Google Play (http://www.everettprogram.org/yei/). These two examples speak to the different ways in which CES findings might be utilized or shared with different audiences outside of the academy.

Finally, CES is explicitly in "direct support of equity-oriented change agendas" (Warren, 2018 , p. 440). Scholarship is not produced for its own sake, rather it is designed to have an impact on social issues with an emphasis on supporting communities that have been historically marginalized. CES is grounded in the assumption that research is inherently political (Gitlin, 1994), and CES practitioners do not pretend to be neutral or apolitical. This approach sometimes results in relational tensions with researchers partnering with stakeholders on one project, while raising critical questions with the same partner on another topic. For example, in 2018 the Research Alliance for New York City Schools partnered with the New York City Department of Education (NYC DOE) to redesign the Annual NYC School Survey focused on school climate. One year prior, when the NYC DOE released a diversity plan that included the expansion of a "diversity in admissions" program through the use of weighted admission criteria, the Research Alliance critically analyzed the impact of the pilot program by exploring both results related to racial and socioeconomic integration and whether or not "these efforts promote more equitable learning opportunities and outcomes for students" (The Research Alliance for New York City Schools, 2017). While occasionally leading to tensions with different policy actors, the capacity 
to forge strategic alliances allows CES practitioners to remain focused on their change agendas. Collectively, this overview of basic principles helps us to better understand what types of research are truly examples of CES.

\section{The Benefits of Community-Engaged Scholarship}

There are many reasons why both researchers and community members may be drawn to CES. First, the meaningful mutual benefits that can identified and derived from CES are appealing to many practitioners. Researchers can gain both access and unique insights that they might otherwise miss without community participation, and community members can have more agency and voice in the research process. CES has a long history in the field of community health, where partnerships are deemed vital for "ensuring discoveries are translated into policies at the practice and community level" (DiGirolamo, Geller, Tendulkar, Patil, \& Hacker, 2012, p. 301). Since educators and community stakeholders are often the populations who are most heavily impacted by justice issues and because they frequently serve as policy implementers, it makes sense to engage them throughout the research process (Coburn, 2005; Lipsky, 1980). Community involvement helps to critically extend the knowledge base that informs research projects. For example, in New York City, the Polling for Justice (PFJ) participatory action research project brought together diverse stakeholders (e.g., PhD researchers, public health specialists, and youth activists) to conduct a quantitative and qualitative survey examining youth experiences with educational, criminal, and health injustices. In reflecting on the intermingling of knowledge from the academy and from youth, members of the research team stated:

If, for instance, there were no youth on the research team, questions about relations with police would not have been asked and analyses would not have been made with the same depth and clarity. With a diverse and multigenerational research team informed by lived experience, traditional bases of scientific knowledge, and critical theory/methods, we believe our "expert validity" was enhanced as the academic monopoly on knowledge was challenged (Stout, Fox, \& Fine, 2012, p. 182)

CES can also encourage grassroots innovation (Martiskainen, 2017). In the early 2000s when the Logan Square Neighborhood Association (LSNA) and Action Now organizers in Chicago first started to research why their local schools were underperforming, it is unlikely that they ever imagined the creation of a program like Grow Your Own (GYO). Ongoing dialogues with local school leaders revealed the challenge of high turnover rates among teachers, an issue that made it difficult to gain traction with and sustain reform efforts. When various attempts at changing recruitment and training strategies failed, Action Now organizers working in partnership with Nueva Generacion, Chicago State University, LSNA, and Chicago Public Schools developed an idea to recruit and train teachers directly from the community using an innovative new teacher preparation program designed to meet the needs of both local teacher candidates and the local schools (Skinner, 2010). The program received significant funding starting in 2006, and the program quickly scaled up to include over ten sites from around Illinois. Unfortunately, a budget impasse in 2015 resulted in the closing of the GYO programs, but it still stands as an example of the type of innovation that can result from CES.

In addition to benefits already described, CES can also serve as a means to provide a counter-narrative to dominant research/policy trends and storylines (Anderson, 2017; Herr, 2017). Education reform in the United States is currently being driven by neoliberal agendas that favor free-market practices and benefit private interests. Charter schools, school voucher programs, and high-stakes testing are just a few examples of policies that are presented as enhancements for consumer choice, but that also benefit for-profit business interests (Hobson, 
Foster, Howard, Wright, Dykos, \& Hudson, 2016; Ross \& Gibson, 2007). These dominant policies are often framed as addressing a taken-for-granted phenomenon like the achievement gap, but CES can offer critically important counter narratives. Working with incarcerated women at a maximum security prison, Michelle Fine and María Elena Torre (2004) developed a research collaborative that focused on the impact of a "college in prison" program and inequities in public education. Through this project, the researchers reframed research questions to help surface counter narratives. "The dominant explanation holds that a student's race, ethnicity and class predict academic engagement, motivation, connection to school, preparedness for college.... To widen the analytic lens, however, and decenter this dominant explanation, we asked students to help us explain the observed race/ethnicity/class differences. They escorted us to an alternative explanation: tracking in suburban high schools" (Fine \& Torre, 2004, p. 22). The researchers found that tracking and access to academic rigor were actually better predictors of student success than race and ethnicity, raising critical questions regarding taken-for-granted policies that exist in most K-12 public schools. It is these sorts of counter narratives that must be developed and shared in order to disrupt oppressive educational practices.

\section{Critiques and Criticisms}

While there are numerous benefits to CES, it is not without its detractors. A common criticism of CES, in particular CES with a clearly articulated advocacy agenda, is that this approach does not meet rigorous research standards. In part, this critique is grounded in historical debates regarding the philosophies of positivism and post-positivism in research. Within the positivist paradigm, researchers strive to apply purportedly objective methodologies commonly used in the natural sciences. From this perspective it is imperative that researchers remain independent from their research subjects to achieve rigor and validity. While the philosophy of positivism peaked in the early $20^{\text {th }}$ century, randomized, controlled research designs continue to be referred to as the "gold standard" of evidence within both the natural and social sciences. Today the impact of this philosophy on the field of education is readily observed in the emphasis on data-driven decision making in schools, an approach linked to accountability-based education policies (Earl \& Katz, 2002; Wayman \& Stringfield, 2006). While the collection of data to inform educators is certainly important, many argue that the privileged metrics of large-scale, quantitative, standardized test scores may actually hinder sustainable educational change efforts and potentially obscure other important social factors (Shirley \& Hargreaves, 2006).

The reality is that it is difficult to disentangle science and politics. Society influences who gets to become a researcher, how science is conducted, and what is prioritized through funding (Sabbagh, 2017). Post-positivists argue that the application of the scientific method is complex and that researchers should consider how context and inherent biases prevent truly objective research. There is recognition that a researcher's background and knowledge influences their engagement in the research process; yet, for many social scientists "good" research continues to be framed through narrow definitions of reliability, validity, and rigor. Research is deemed reliable if the findings of a study can be replicated, while validity relates to confidence in the accuracy of the findings (Merriam, 1998).

However, when questions are raised as to whether or not CES is biased, supporters argue that it is more important to focus on rigor. From this perspective, CES might even have an edge over research that lacks community engagement: 
Collaborative research can be considered more rigorous than more traditional forms because it must demonstrate its credibility to a broader audience that brings a more diverse set of questions and standpoints to bear. In collaborative work, there is accountability to partners and to the demands of practice (Warren et al., 2018, p. 448).

An exploration of multiple research projects utilizing CES concludes that community engagement has the potential to increase academic rigor by making biases more explicit, enhancing research designs, increasing accountability, and creating more trustworthy relationships (Jagosh, et al., 2012; Warren et al., 2018). As noted above, no research is completely objective, so it is important for researchers to critically reflect on their underlying assumptions and to actively seek to address these biases. Through ongoing conversations, relationship building, and the intentional creation of spaces that allow for the presence and discussion of partnership tensions, practitioners of CES can reduce the impact of their biases. It is important to explicitly name these biases, so as not to recreate the shroud of purported objectivity. The overall rigor of the research design can also be improved based on the inclusion of the perspectives of those who are closest to the challenges that are under examination. As Fine writes, "Critical participation by those who most intimately know injustice not only strengthens the political depth and ethics of a project, but also the validity of the science and the sustainability of the findings" (Fine, 2015, p. 10). Finally, CES creates an additional level of accountability that extends beyond the peer-review process. Research produced via CES addresses issues that are important to communities, recognizes and honors the knowledge that exists within communities, and is disseminated in ways that are beneficial to all stakeholders (Israel, Schulz, Parker, \& Becker, 1998).

\section{Central Challenges for CES in Family, School \& Community Partnerships}

While many criticisms of CES are not valid, this does not mean that there are not legitimate challenges that are faced by those who seek to do this work. In this section, some of these challenges are discussed using the lens of the Belmont Report as it might be reimagined by practitioners of CES (National Institutes of Health, 1979). The Belmont Report was selected as an appropriate heuristic device for examining challenges in CES, since it provides a well known starting point for researchers thinking about ethical considerations and guidelines for working with human research subjects. However, a critical interpretation of the document is necessary as it is imperative for CES researchers to act ethically in ways that extend the recommendations of the Belmont Report, a document that focuses on individual protections for human subjects. While the report's core principles of respect for persons, beneficence, and justice remain applicable, they are limited in scope because CES partners are framed as subjects, and there are no guidelines for considering the potential impact of research on communities as a whole (Hacker, 2013; Shore, 2006).

\section{Respect for Persons}

Respect for persons traditionally includes making sure that research participation is voluntary, that requirements for informed consent are met, and that there are sufficient protections for special populations (e.g., prisoners or children). In extending this definition, within CES there must be respect for the entire community and participants should be treated as full partners. This can sometimes be complicated, as defining "community" is not always a straightforward process. People possess multiple identities, and even those with shared interests may define what constitutes a particular community differently. What is clear is that a single gatekeeper cannot provide consent of the behalf of a community. Obtaining the consent of the community should be a negotiated process that is inclusive of diverse community stakeholders 
who may hold formal or informal roles. This might include key leaders and representatives from a community-based organization or the development of a community advisory board (Hacker, 2013).

Respect also means that community partners must be treated as full partners. To accomplish this goal, there are issues of power that must be attended to through the creation of processes that respect the contributions of all. This is of particular importance, since university researchers likely possess financial resources and other forms of capital that privilege their positionality. Depending upon of the composition of the partnership, there will also likely be a range of relational power dynamics among stakeholders that will need to be considered, including race, ethnicity, religious affiliation, gender, sexual orientation, social class, and professional status. Issues related to these dynamics can emerge in varied and continuous ways, so it is important for CES participants to remain vigilant in maintaining respectful relationships. For example, time as a resource is one issue that could surface. CES can demand a significant time investment that communities are unable or unwilling to make. A community-based organization ( $\mathrm{CBO}$ ) may be engaged in other advocacy or activist efforts and may not have the time to fully commit to every aspect of the research process. In fact, a CBO may enter into a research partnership because of the recognition that they do not have time to do everything; however, another CBO may seek to be an active participant in every step of the research process. Individual contributors may feel pressured for time due to other family or job-related commitments. In either case, it is necessary to respect the desires of the community members, and CES participants should negotiate expectations upfront and periodically revisit these agreements to make sure that the needs of partners are being met.

\section{Beneficence}

The concept of beneficence typically address the minimization of risk and maximization of benefits produced from the research. Researchers must demonstrate that the potential benefits of a project outweigh any risks. In the social sciences, it is frequently easier to limit risk than to demonstrate concrete benefits; yet in CES, it is imperative for all stakeholders to reap benefits from their participation. Addressing gaps in the research literature is not sufficient rationale for research with an equity-oriented, change agenda. Again, ongoing dialogues must take place to determine expected benefits and desired outcomes.

CES practitioners must also anticipate and be prepared to address unintended consequences of their work. As Hacker notes, there are often benefits to be derived from research, yet "community 'harm' is also a possibility and is often unanticipated. The results of research have the potential to stigmatize a community or group if findings are disparaging" (2013, p. 114). For example, a study of family participation in school-based activities might inadvertently further marginalize and even put at risk an immigrant community that chooses not to participate based on their undocumented status. Participants in CES must carefully consider potential audiences for their research and how findings will be shared. Similarly, a less-thanpositive evaluation on the effectiveness of a community project might create tensions between scholars and community members. A scholar has a responsibility to both the community and a wider audience to share the findings, while community stakeholders might be more concerned about the immediate impact on the community. These types of tensions are unavoidable, and thus, a careful consideration of risks and benefits is important.

\section{Justice}

Finally, in research, the concept of justice seeks to ensure that the selection of research participants is fair. When working with special populations (e.g., students), researchers might be 
asked to explain why it is necessary to focus a study on a particular group. With CES this is typically less of an issue since the participants become partners in the research process; although, justice concerns can still emerge if a collective starts to do research in their community with people who are not already involved in the work. The justice concept also calls for an equitable distribution of the benefits and burdens of the research. This concern is shared in the related concepts of respect and beneficence outlined above.

While partners in CES may share values, goals, and purposes with regard to research endeavors, determining specific research products (reports, websites, policy briefs, news articles, etc.) and how results will be disseminated can still be a challenge (Minkler, 2005). For example, in thinking about family, school, and community partnerships, researchers in tenure-track positions may feel compelled to publish in academic peer-reviewed journals. Publication in such venues is often an institutional requirement for career advancement in academia. However, community members might be more interested in developing and utilizing surveys that can generate data that they can use at an upcoming school board meeting. Community needs are often more immediate and require quick action since community activists must be able to react to shifting policy opportunities. Since community members are sharing the burdens of the research, it is important that they also share in meaningful benefits. While the academy is slowly becoming more accepting of publically engaged scholarship, there is still much work to be done in this area. Experienced practitioners of CES have started to develop tools to better support the evaluation of publicly engaged scholarship in academia (Eatman, Ivory, Saltmarsh, Middletown, Wittman, \& Dolgon, 2018). However, it is still advisable for researchers and community stakeholders to negotiate mutually beneficial research projects upfront to avoid future misunderstandings.

While there are challenges that must be addressed in CES, if stakeholders are able to effectively navigate these issues, there is the potential to achieve impactful social change. Successful CES is based on a foundation of strong relationships and trust. It is in the initial stages of emerging partnerships where communication is crucial, as stakeholders negotiate their roles, contributions, and expectations. These conversations are critical in order to avoid, or at least temper, possible tensions. It is also important for practitioners of CES to embed regular opportunities for continued reflection and evaluation on these issues. The institutional review boards (IRB) at most universities or organizations are ill-equipped to evaluate CES proposals, so researchers and community members must be prepared to supplement this work with their own assessments that speak to these challenges (Flicker, Travers, Guta, McDonald, \& Meagher, 2007). Fortunately, in recognition of this knowledge gap, experienced groups like the Detroit Urban Research Center, the Public Science Project (at the CUNY Graduate Center in NYC), and the Everett Program at UC Santa Cruz are offering training and workshops for both researchers and community members seeking to implement or improve CES practices in their work. Moreover, in 2015 the CITI program (which provides online IRB training for many universities and organizations) started to offer three training modules focused on CES that were developed in collaboration with the Harvard Catalyst Community Engaged Research Subcommittee, and other similar training opportunities continue to proliferate.

\section{Conclusion}

Over the past fifteen years, research in the field of family, school, and community partnerships has begun to evolve in recognition of the need for more authentic partnership work to meet the needs of all students. This is particularly true when working with historically marginalized populations that do not meet traditional white, middle-class norms related to family involvement. It is clear that there is a continued need for definitions of family engagement to be 
reimagined. Education policymakers have also started to recognize the importance of supporting capacity building for both educators and families, but there is much work that remains to be done as communities and educators struggle to address critical issues such as immigration, the opportunity gap, and the school-to-prison pipeline. CES offers an opportunity for communities, educators, and researchers to work together to initiate or support the furthering of these efforts. Through the transformation of the relational dynamics between researchers and communities, the recognition and honoring of multiple forms of knowledge, and an explicit commitment to equity oriented research agendas, new collaborations can be forged that will advance the field and benefit a broad range of public education stakeholders. 


\section{References}

Anderson, G. (2017). Participatory action research (PAR) as democratic disruption: New public management and educational research in schools and universities. International Journal of Qualitative Studies in Education, 30(5), 432-449. doi: 10.1080/09518398.2017.1303211

Anderson, G. L. (2009). Advocacy leadership: Toward a post-reform agenda in education. New York, NY: Routledge.

Auerbach, S. (2001) Under co-construction: parent roles in promoting college access for students of color. (Unpublished doctoral dissertation). University of California, Los Angeles.

Auerbach, S. (Ed.). (2012). School leadership for authentic family and community partnerships: Research perspectives for transforming practice. New York, NY: Routledge.

Auerbach, S., \& Collier, S. (2012). Bringing high stakes from the classroom to the parent center: Lessons from an intervention program for immigrant families. Teachers College Record, 114(3), 1-40.

Bertrand, M., Freelon, R., \& Rogers, J. (2018). Elementary principals' social construction of parents of color and working class parents: Disrupting or reproducing conflicting and deficit orientations of education policy? Education Policy Analysis Archives, 26, 102.

Coburn, C. E. (2005). Shaping teacher sensemaking: School leaders and the enactment of reading policy. Educational Policy, 19(3), 476-509.

Cooper, C. W., \& Christie, C. A. (2005). Evaluating parent empowerment: A look at the potential of social justice evaluation in education. Teachers College Record, 107(10), 22482274.

Crowson, R. L., \& Boyd, W. L. (2001). The new role of community development in education reform. Peabody Journal of Education, 76, 9-29. doi: 10.1207/S15327930pje7602_2

Delgado Bernal, D. (1997). Chicana school resistance and grassroots leadership: providing an alternative history of the 1968 East Los Angeles blowouts. (Unpublished doctoral dissertation) University of California, Los Angeles.

Delgado Bernal, D. (2001). Living and learning pedagogies of the home: The mestiza consciousness of Chicana students. International Journal of Qualitative Studies in Education, 14(5), 623-639.

Denzin, N. (2017). Critical qualitative inquiry. Qualitative Inquiry, 23(1), 8-16.

DiGirolamo, A., Geller, A. C., Tendulkar, S. A., Patil, P., \& Hacker, K. (2012). Community based participatory research skills and training needs in a sample of academic researchers from a clinical and translational science center in the northeast. Clinical and Translational Science, 5(3), 301-305.

Earl, L. \& Katz, S. (2002). Leading schools in a data-rich world. In K. Leithwood \& P. Hallinger (Eds.), Second International Handbook of Educational Leadership andAdministration. Dordrecht, Netherlands: Kluwer Academic Publishers.

Eatman, T. K., Ivory, G., Saltmarsh, J., Middletown, M., Wittman, A., \& Dolgon, C. (2018). Coconstructing knowledge spheres in the academy: Developing frameworks and tools for advancing publically engaged scholarship. Urban Education, 53(4), 532-561. 
Fan, W., \& Williams, C. M. (2010). The effects of parental involvement on students' academic self-efficacy, engagement and intrinsic motivation. Educational Psychology, 30(1), 53-74.

Faulstich Orellana, M. (2003). In other words: en otras palabras: learning from bilingual kids' translating/interpreting experiences. Evanston, IL: School of Education and Social Policy, Northwestern University.

Fine, M. (2015). Global provocations: Critical reflections on community based research and intervention designed at the intersections of global dynamics and local cultures. Community Psychology in Global Perspective, 1(1), 5-15.

Fine, M., \& Torre, M. E. (2004). Re-membering exclusions: Participatory action research in public institutions. Qualitative Research in Psychology, 1(1), 15-37.

Flicker, S., Travers, R., Guta, A., McDonald, S., \& Meagher, A. (2007). Ethical dilemmas in community-based participatory research: Recommendations for institutional review boards. Journal of Urban Health, 84(4), 478-493.

Gitlin, A. (Ed.). (1994). Power and method: Political activism and educational research. New York, NY: Routledge.

Hacker, K. (2013). Community-based participatory research. Thousand Oaks, CA: SAGE.

Henderson, A. T., \& Mapp, K. L. (2002). A new wave of evidence: The impact of school, family, and community connections on student achievement. Annual Synthesis, 2002.

Herr, K. (2017) Insiders doing PAR with youth in their schools: negotiating professional boundaries and healing justice. International Journal of Qualitative Studies in Education, 30(5), 450-463, doi: 10.1080/09518398.2017.1303213

Hobson, S., Foster, S., Howard, J., Wright, D. E., Dykos, B., \& Hudson, E. (2016). Introduction to the special issue: Challenging neoliberal reforms through collaborative, community engaged research. International Journal of Qualitative Studies in Education, 29(10), 12331240.

Huss-Keeler, R. L. (1997). Teacher perception of ethnic and linguistic minority parental involvement and its relationships to children's language and literacy learning: A case study. Teaching and Teacher Education, 13(2), 171-182.

Israel, B. A., Schulz, A. J., Parker, E. A., \& Becker, A. B. (1998). Review of community-based research: assessing partnership approaches to improve public health. Annual Review of Public Health, 19(1), 173-202.

Jagosh, J., Macaulay, A. C., Pluye, P., Salsberg, J., Bush, P. L., Henderson, J., ... \& Seifer, S. D. (2012). Uncovering the benefits of participatory research: implications of a realist review for health research and practice. The Milbank Quarterly, 90(2), 311-346.

Kosciw, J. G., \& Diaz, E. M. (2008). Involved, invisible, ignored: The experiences of lesbian, gay, bisexual and transgender parents and their children in our nation's K-12 schools. New York, NY,: Gay, Lesbian and Straight Education Network (GLSEN).

Kroeger, J. (2006). Stretching performances in education: the impact of gay parenting and activism on identity and school change. Journal of Educational Change, 7(4), 319-337.

Lareau, A. (2011). Unequal childhoods: Class, race, and family life. Berkeley, CA: University of California Press. 
Li, G. (2010). Social class, culture, and "good parenting": Voices of low-SES families. In M. Marsh \& T. Turner-Vorbeck (Eds), (Mis)understanding families: Learning from real families in our schools (pp. 162-178). New York, NY: Teachers College Press.

Lipsky, M. (1980). Street-level bureaucracy: Dilemmas of the individual in public services. New York: Russell Sage

Mapp, K. L. \& Kuttner, P. J. (2014). Partners in education: A dual capacity building framework for family-school partnerships. Washington, DC: U.S. Department of Education.

Martiskainen, M. (2017). The role of community leadership in the development of grassroots innovations. Environmental Innovation and Societal Transitions, 22, 78-89.

McFee, G. (1992). Triangulation in research: two confusions. Educational Research, 34(3), $215-$ 219.

Merriam, S. B. (1998). Qualitative research and case study applications in education. San Francisco, CA: Jossey-Bass.

Minkler, M. (2005). Community-based research partnerships: challenges and opportunities. Journal of Urban Health, 82(2), ii3-ii12.

Moll, L. C., Amanti, C., Neff, D., \& Gonazalez, N. (1992). Funds of knowledge for teaching: Using a qualitative approach to connect home and classrooms. Theory into Practice, 31(2), 132-141.

National Institutes of Health. (1979). The Belmont report: Ethical principles and guidelines for the protection of human subjects of research. Bethesda, MD: U.S. Department of Health \& Human Services.

Peralta, K. J. (2017). Toward a deeper appreciation of participatory epistemology in community based participatory research. PRISM: A Journal of Regional Engagement, 1(6), 45-56. Retrieved from https://encompass.eku.edu/prism/vol6/iss1/4

The Research Alliance for New York City Schools. (2017, September 12). Who Are the "Diversity in Admissions" Pilot Schools? Retrieved from https://steinhardt.nyu.edu/site/research_alliance/2017/09/12/who-are-the-diversity-in admissions-pilot-schools/

Rogers, J. (2006). Forces of accountability? The power of poor parents in NCLB. Harvard Education Review, 76(4), 611-641.

Rogers, J., Fanelli, S., Freelon, R., Medina, D., Bertrand, M., \& Del Razo, M. (2010). Educational opportunities in hard times: The impact of the economic crisis on public schools and working families. Los Angeles: UCLA/IDEA, UC/ACCORD.

Ross, E. W. \& Gibson, R. J. (Eds.). (2007). Neoliberalism and education reform. Cresskill, NJ: Hampton Press.

Sabbagh, U. (2017). Science has always been inseparable from politics. Scientific American. Retrieved from https://blogs.scientificamerican.com/guest-blog/science-has-always-beeninseparable-from-politics/

Sheldon, S. B. (2003). Linking school-family-community partnerships in urban elementary schools to student achievement on state tests. The Urban Review, 35(2), 149-165. 
Shirley, D. (2009). Community organizing and educational change: A reconnaissance. Journal of Educational Change, 10(2-3), 229-237.

Shirley, D., \& Hargreaves, A. (2006). Data-driven to distraction. Education Week, 26(6), 32-33.

Shore, N. (2006). Re-conceptualizing the Belmont Report: A community-based participatory research perspective. Journal of Community Practice, 14(4), 5-26.

Skinner, E. A. (2010). Project Nueva Generacion and grow your own teachers: Transforming schools and teacher education from the inside out. Teacher Education Quarterly, 37(3), 155 167.

Sloane, J. A. \& Wallin, D. (2013). Theatre of the commons: A theatrical inquiry into the democratic engagement of former refugee families in Canadian public high school communities. Educational Research, 55(4), 454-472. doi: 10.1080/00131881.2013.844948

Solórzano, D. \& Delgado Bernal, D. (2001). Critical race theory, transformational resistance and social justice: Chicana and Chicano students in an urban context. Urban Education, 36, 308342.

Stanton-Salazar, R. D. (2001). Manufacturing hope and despair: the school and kin support networks of US-Mexican youth. New York, NY: Teachers College Press.

Stoudt, B. G., Fox, M., \& Fine, M. (2012). Contesting privilege with critical participatory action research. Journal of Social Issues. 68(1), 178-193.

Wayman, J. C. \& Stringfield, S. (2006). Data use for school improvement: School practices and research perspectives. American Journal of Education, 112(4), 463-468.

Warren, M. R. (2018). Research confronts equity and social justice-Building the emerging field of collaborative, community engaged research: Introduction to the special issue. Urban Education, 53(4), 439-444.

Warren, M. R., Calderón, J., Kupscznk, L. A., Squires, G., \& Su, C. (2018). Is collaborative, community-engaged scholarship more rigorous than traditional scholarship? On advocacy, bias, and social science research. Urban Education, 53(4), 445-472.

Warren, M., Hong, S., Rubin, C. L., \& Uy, P. S. (2009). Beyond the bake sale: A community based relational approach to parent engagement in schools. Teachers College Record, 111(9), 2209-2254.

Warren, M. R. \& Mapp, K. L. (2011). A match on dry grass: Community organizing as a catalyst for school reform. New York, NY: Oxford University Press.

Yosso, T. J. (2005). Whose culture has capital? A critical race theory discussion of community cultural wealth. Race, Ethnicity and Education, 8(1), 69-91. 